\title{
Enfermedad Neuroinvasiva por Virus del Nilo Occidental: por qué debería considerarse en la Península lbérica
}

\author{
West Nile Virus Neuroinvasive Disease: \\ why it should be considered in the Iberian Peninsula
}

\begin{abstract}
João Matos ${ }^{1,5}$, Cândida Abreu²,3,
${ }^{1}$ Faculdade de Medicina. Universidade do Porto. Porto. Portugal. ${ }^{2}$ Serviço de Doenças Infeciosas. Centro Hospitalar São João. Porto. Portugal. ${ }^{3}$ Departamento de Medicina - Faculdade de Medicina. Universidade do Porto. Porto. Portugal. ${ }^{4}$ Instituto de Inovação e Investigação em Saúde (I3S). Instituto Nacional de Engenharia Biomédica (INEB). Porto. Portugal. ${ }^{5}$ Serviço de Doenças Infeciosas. Centro Hospitalar Universitário do Porto. Porto. Portugal
\end{abstract}

\begin{abstract}
Introduction: West Nile virus has caught attention given the spike of European cases in the season of 2018. The number of infected humans exceeded the total cases of the past seven years and the virus expanded to area previous disease-free, causing significant morbimortality.

Objectives: To highlight from a clinical standpoint West Nile virus as a possible aetiology in neuroinvasive disease on humans in the Iberian Peninsula.

Materials and Methods: Data was obtained from Centres for Disease Control and Prevention and the European Centre for Disease Prevention and Control and it was conducted a review of the literature in PubMed electronic database.

Results and Discussion: West Nile virus can be transmitted by mosquitoes' bites, blood transfusion, and organ transplant. Although most infections are asymptomatic, $<1 \%$ of patients develop neuroinvasive disease presenting as meningitis, encephalitis or acute flaccid paralysis. West Nile virus should be considered as a differential diagnosis in the face of neurological symptoms of unknown aetiology in the appropriate epidemiological circumstances. Diagnosis in the clinical setting is based in serological analysis. As available treatment is only supportive, preventive measures are key to diminish this virus' impact. The future of West Nile virus is difficult to predict, even though ongoing global changes could be factors influencing its course.

Conclusion: West Nile virus depicts the unpredictability around zoonotic diseases, hence, justifying the need of further surveillance and information in the Iberian Peninsula, considering the existence of the vector and the already recorded human/animal cases.
\end{abstract}

Keywords: West Nile virus, Meningitis, Encephalitis, Acute Flaccid Paralysis, Iberian Peninsula.

\section{INTRODUCTION}

The year of 2018 was unprecedented as the number of human cases of West Nile virus (WNV), 2083 autochthonous cases reported in Central and Southern Europe (Fig.1), surpassed the previous seven years all together (2010-2017), affecting new areas, and being a factor of severe morbimortality (181 deaths reported).

Figure 1. Number of WNV infections in European Union/ European Economic Area Member States and European Union neighbouring countries by epidemiological week of notification (to national authorities or if missing, week of notification to European Centre for Disease Prevention and Control - ECDC), 2014-2018. Graphic and data from the ECDC. WNV- West Nile virus

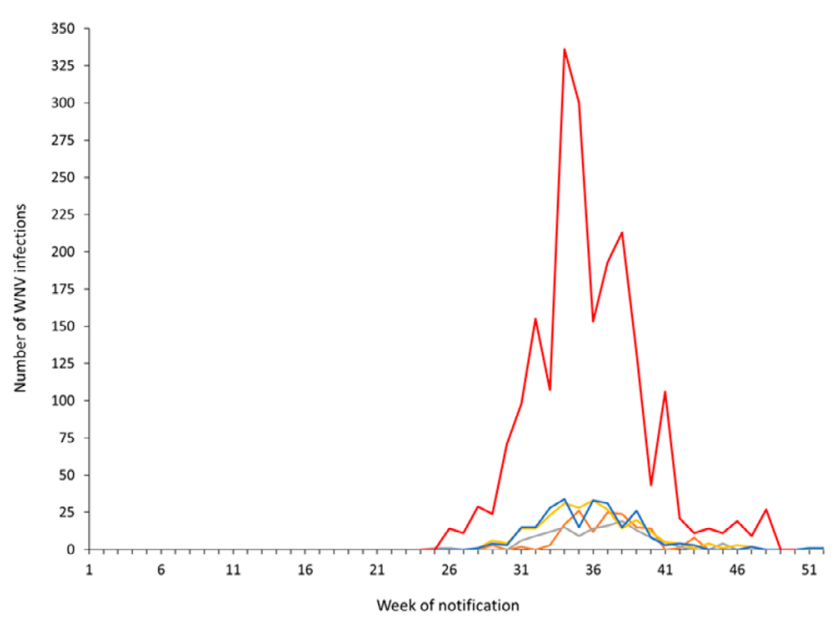

WNV is considered as a good example of how an apparently stable zoonosis can emerge with unpredictable consequences. Most infected individuals are asymptomatic, however, it is important to be recalled as a differential diagnosis in the case of WNV's neuroinvasive manifestations, to prevent iatrogenic complications from misdiagnoses and subsequent therapies ${ }^{1}$. The virus has been known to cause occasional outbreaks especially in countries of Central and Southern Europe. In those European countries, WNV raises more awareness than in Iberian Peninsula, even though human cases have been described and the virus is known to be in circulation ${ }^{2,3}$. Hence, there is a growing concern over the future of WNV in whether global changes will increase the human and animal impact of this disease.

The WNV is a neurotropic arthropod-borne flavivirus genetically related to the Japanese encephalitis virus. It has a transmission cycle which comprises several species of wild migratory and/or resident birds (reservoir host) and mainly the Culex mosquitoes species (vector); humans and mammals like horses may be infected by these mosquitoes' bites, however they do not play a part on further transmission because their short-timed low level viremia does not allow it, being described as "dead-end hosts".

WNV was first isolated from a human patient in 1937 in the West Nile district of Uganda, and from that point onwards it has been detected in several regions of the World even in the American continent in $1999^{1}$. In the past, the virus was mostly 
spread via migratory birds that overwinter in Africa which contributed to the usual WNV season of activity in Europe, ranging from mid-June to mid-November which matches with the birds' return and also with the vectors peak of activity, ${ }^{5,6}$. Nowadays, the virus is endemic to the Old Continent (Fig.2) ${ }^{4}$.

Figure 2. Distribution of West Nile virus infections in humans by affected areas in the European Union/ European Economic Area Member States and European Union neighbouring countries in the transmission season of 2018 and previous ones (with overlap); latest data update 13 December 2018. Map and data from the ECDC.

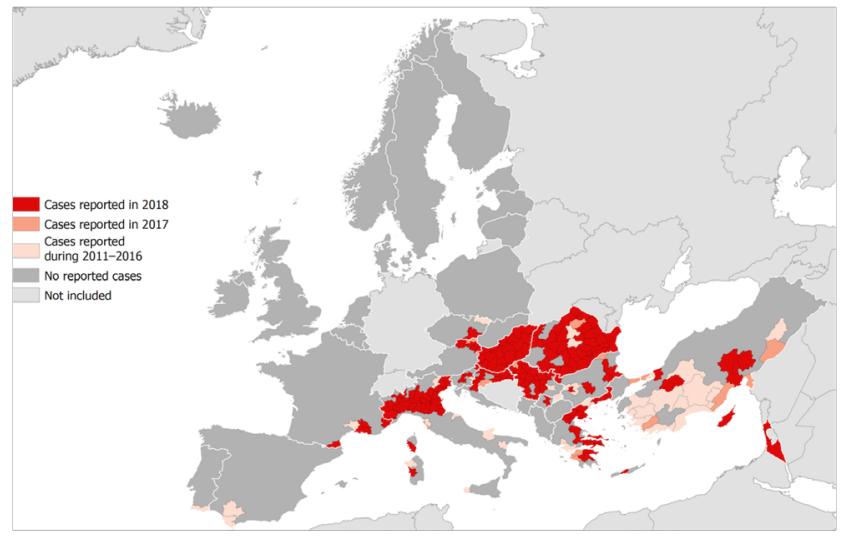

This manuscript intends to highlight from a clinical standpoint WNV infection as a differential diagnosis in the case of meningitis, encephalitis or acute flaccid paralysis, given the recent spike of cases in Europe, that might propel a greater spread of the virus in the Iberian Peninsula, considering the disseminated vector presence in the region.

\section{METHODS}

To fulfil this objective, data related to WNV epidemics and current recommendations were obtained on the websites of the Centres for Disease Control and Prevention and the European Centre for Disease Prevention and Control (ECDC) and it was conducted a review of the literature in PubMed electronic database using the terms: West Nile virus, West Nile fever, neuroinvasive disease, meningitis, encephalitis and acute flaccid paralysis. Articles written in English and Portuguese were analysed with publication date till February 2019. There were no restrictions on the type of study. Additional studies found in the references of the selected ones and pertinent book chapters were also included.

\section{RESULTS AND DISCUSSION}

\section{Epidemiology Matters}

Anamnesis is key to consider WNV as a differential diagnosis. Location of patient's residence and travel history is of utmost importance in order to verify his presence in an area with active transmission - this factor may make or break the diagnostic hypothesis? ${ }^{7}$. Therefore, in the Iberian Peninsula, local cases as much as imported ones must be considered. In order to identify a WNV infection it is important to recognize and comprehend its clinical presentations, however, it could be difficult to discriminate each one since overlap is common ${ }^{8}$.
Figure 3. Resume of the characteristics of WNV infection, focusing on neuroinvasive disease and a short scheme of diagnostic work-up.

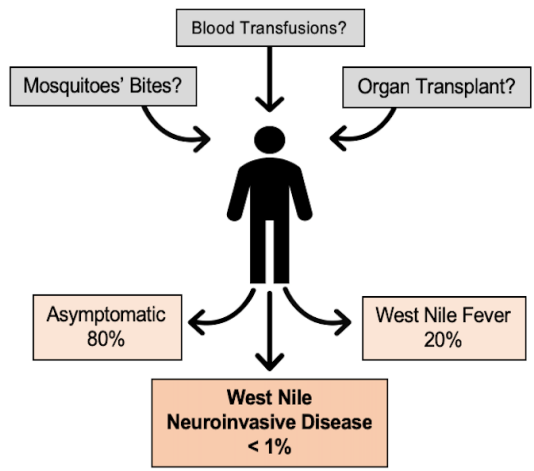

\begin{tabular}{|c|c|}
\hline \multicolumn{2}{|c|}{ Presents as meningitis and/or encephalitis and/or acute flaccid paralysis } \\
\hline Season of the year & Primarily between mid-June to mid-November. \\
\hline Incubation period & 2 to 14 days, longer in immunocompromised patients. \\
\hline "Not entirely exclusive of each presentation & $\begin{array}{l}\text { Meningitis } \\
\text { Encephalitis } \\
\text { - Acute Flaccid Paralysis - muscle weakness (limbs, cranial } \\
\text { or respiratory muscles); dysarthria, dysphagia, loss of gag } \\
\text { reflex; bladder and bowel disfunction; preserved sensory } \\
\text { function. }\end{array}$ \\
\hline
\end{tabular}

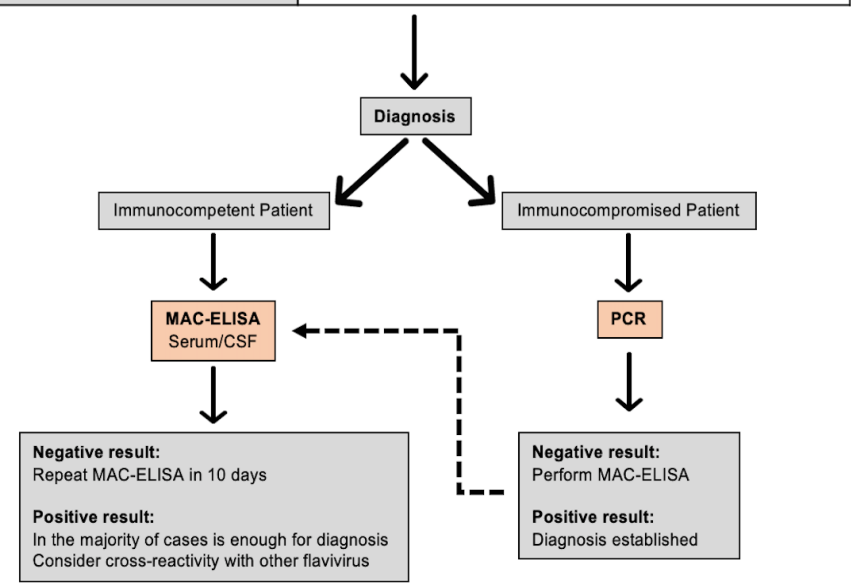

\section{The Virus and Transmission Routes}

The virus is generally introduced in humans by a mosquito bite and the infection can be characterized in three phases: early phase - it infects skin cells in the point of entry; visceral dissemination phase - the virus spreads to the nearest lymphatic node from which it cause viremia followed by organs invasion such as the central nervous system (CNS), in which it presents as neuroinvasive disease - the CNS phase ${ }^{9}$. This last phase is the most important because of its clinical repercussion.

While mosquito bites are the most common route of infection (Fig.3), WNV can be spread by transfusions of diverse products obtained from blood of infected donors ${ }^{10}$. Countering this risk, a European directive (2004/33/EC) states that travellers who return from an area with ongoing transmission of WNV should be deferred from donating blood for 28 days. Bearing in mind a blood donations shortage, nucleic acid amplification techniques (such as polymerase chain reaction - PCR) to detect WNV RNA can be implemented in WNV affected 
countries and in countries without active transmission but with a considerable number of travellers returning from those areas, as the WNV peak of activity coincides with the high travel season in Europe.

Two other ways of transmission, although rare, should be kept in mind. One is through solid organ transplant from an infected individual, which could be particularly dangerous as patients are deeply immunocompromised ${ }^{11}$. Infection has been reported through organs from a donor with no traceable WNV RNA but detectable immunoglobulin (lg) M/lgG anti-WNV which highlight the complexity involving transplantation and WNV control, as the virus may reside hidden in organs after viremia was cleared or by long-term persistence of WNV characterized by a sporadic viremia ${ }^{12}$. Therefore, implementing a screening test to donors is difficult and probably not cost-effective ${ }^{13}$. The other is vertical transmission, an even rarer possibility, with very few possible intrauterine and breastfeeding infections which could neither be excluded or confirmed, requiring more reports and investigation ${ }^{14}$.

\section{Clinical Manifestations}

Symptoms and signs are only detectable after an incubation period which can vary from 2 to 14 days, but it can go up to 21 days in immunocompromised patients ${ }^{10}$. Most infected patients will remain asymptomatic (around 80\%) so it is only possible to verify its infection by a blood screening mostly performed in situations concerning blood donations ${ }^{8}$.

The most common presentation is West Nile fever (WNF) in about $20 \%$ of infected patients, characterized as a flu-like syndrome with a sudden onset of fever (which may be of low grade), fatigue, headache, and myalgia ${ }^{15}$. Other symptoms include nausea, vomiting, and a morbilliform or maculopapular rash that affects 25 to $50 \%$ of patients ${ }^{16,17}$. The rash tends to be non-pruritic, more prevalent in the head, neck, torso and extremities sparing palms and soles ${ }^{16}$. WNF ranges from a mild condition lasting only a few days to an incapacitating state persisting weeks to months ${ }^{18}$. However, the majority of patients should have a full recovery ${ }^{19}$.

\section{Neuroinvasive Disease}

WNV is able to penetrate the blood-brain barrier affecting the meninges and causing neural parenchymal damage. This is more common in older and immunocompromised individuals $^{20,21}$. WNV neuroinvasive disease may present as meningitis, encephalitis, and acute flaccid paralysis (AFP) or as a combination of these different presentations (Fig. 3). Despite affecting $1 \%$ or less of infected patients, these conditions are the more damaging clinical outcomes ${ }^{18}$.

\section{Meningitis}

Meningitis caused by WNV is similar to a typical viral meningitis, being impossible to distinguish by clinical manifestations. It is characterized by fever and retroorbital or frontal headache, meningeal signs, photophobia, and phonophobia ${ }^{22,23}$. The characteristic rash is less observed comparing to WNF ${ }^{16}$. Constitutional signs may also be present such as abdominal pain, anorexia, myalgia, nausea, and vomits ${ }^{22,24}$.

Encephalitis
In WNV encephalitis, mental status changes are very common and can range from mild confusional state to severe encephalopathy and coma ${ }^{8}$. Behavioural differences such as disorientation, confusion and irritability ${ }^{23}$ are also present. Diffuse and focal neurological manifestations, such as extrapyramidal symptoms with the appropriate epidemiologic context is a very characteristic feature ${ }^{8,23}$. Chronologically, changes in the consciousness level usually presents first and they are followed by movement disorders ${ }^{8,20}$. Bilateral tremor and myoclonus may be present, both more common in the upper extremities and the latter also in facial muscles ${ }^{18,23}$. Patients may develop cerebellar ataxia with gait imbalance and parkinsonism characteristics such as bradykinesia, rigidity, and postural instability which can lead to falls ${ }^{23}$. Seizures, increased intracranial pressure or cerebral oedema are rare ${ }^{8}$. Acute Flaccid Paralysis

Muscle weakness in the form of paresis or paralysis can be observed as an outcome of WNV infection and represents damage dealt to the lower motor neurons of the spinal cord ${ }^{25-}$ 27. On physical examination, this AFP syndrome is typically characterized by hyporeflexia or areflexia of the affected muscles ${ }^{23,25}$. Muscle weakness related to AFP develops in the acute phase of infection, 24 to 48 hours after symptoms onset. It is frequently asymmetric affecting only one limb but might present as quadriplegia ${ }^{18}$. In some particular cases, bilateral cranial muscle weakness may be observed, affecting particularly the muscles innervated by the seventh cranial nerve ${ }^{27}$. Persistent loss of muscular strength leads to muscular atrophy in late stages ${ }^{28}$. However, the most dangerous situation is when respiratory muscles are affected as it propels respiratory failure ${ }^{25,26}$. Invasive mechanical ventilation might be required for prolonged periods or even permanently, increasing mortality and morbidity ${ }^{26}$. It is important to access patients with risk of developing respiratory failure, especially those that concomitantly have dysarthria, dysphagia or loss of gag reflex ${ }^{21}$. Bladder and bowel disfunction are common; pain is reported by some patients; however, modification in sensory sensations are absent for most cases ${ }^{21,23,25}$

\section{Differential Diagnosis}

Summing up, in this stage with the details from patient's history and the presentation of neuroinvasive disease, hypothetical diagnoses can be formulated. At this moment, more attention must be drawn towards WNV.

However, affirming the diagnosis of WNV infection based solely on the clinical manifestations is very challenging: apart from symptoms' lack of specificity, in areas with co-circulation of other flavivirus (dengue, yellow fever, Zika, Japanese encephalitis, St. Louis encephalitis viruses), due to similar clinical outcomes is hard to distinguish between them ${ }^{4,28}$. Many other infectious conditions (such as herpes simplex 1 , enterovirus, varicella zoster and human immunodeficiency viruses or bacteria as meningococcus or pneumococcus) present as meningitis or encephalitis ${ }^{29}$. AFP might also be described as a poliomyelitis-like syndrome for its resemblance with clinical manifestations of poliovirus infection ${ }^{22}$. Patients infected with WNV presenting with AFP can be misdiagnosed 
with Guillain-Barré syndrome (GBS) especially its acute motor axonal neuropathy subtype ${ }^{28}$. However, sensory impairment of GBS is uncommon in AFP, and can be confirmed with physical examination or nerve conduction studies. Myopathies and neuromuscular junction disorders might too be listed as differential diagnoses. This clinical presentation can also be observed in other infectious diseases such as Lyme disease, syphilis, and botulism ${ }^{30}$.

\section{Diagnostic Considerations}

Taking into account the clinical information gathered, the suspicion of WNV infection is confirmed by detection of lgM antibodies anti-WNV in serum or cerebrospinal fluid (CSF) by an IgM antibody-capture enzyme-linked immunosorbent assay (MAC-ELISA) which is sufficient in the majority of cases ${ }^{28,31}$. IgM is highly suggestive of acute infection, rising as early as 4 days to 10 days after symptoms onset; consequently, it is possible to have a negative MAC-ELISA result if the test is performed before the rise of IgM level; in this situation, the test should be repeated days later ${ }^{15,28}$. IgM titres usually decline from the $21^{\text {st }}$ day onwards being undetectable 1 to 2 months after clinical resolution ${ }^{28}$.

An important factor to consider is the possibility of crossreactivity in MAC-ELISA test with other flaviviruses, depicting the importance of patient's travel history and residence area and/or in the event of recent vaccination for Japanese encephalitis/yellow fever virus ${ }^{15,28,31}$. Therefore, a confirmatory test should be requested in order to verify if MAC-ELISA is falsely positive for WNV. Plaque reduction neutralization test (PRNT) indicates the highest dilution of serum able to neutralize WNV among other flaviviruses using cell cultures: the higher the titre, the higher the antibody' serum concentration and the test is considered positive and the diagnosis is confirmed when is documented a difference 4 times greater for WNV than for other flaviviruses tested 28,31 . The problem of PRNT lies with its complexity, demanding a biosafety level 3 laboratory to be performed, limiting its utility ${ }^{31,32}$.

Ultimately, the viremia level can be detected by PCR to prove an acute infection, but humans develop a frail viremia with low concentration of WNV genome material for a short amount of time, so it is considered unpractical in a clinical setting, although being a very specific test ${ }^{31,32}$. Exception could be made when testing an immunocompromised patient, since the development of antibodies is delayed or absent and viremia is sustained for longer periods ${ }^{33}$.

Lumbar punctures can be performed, unless contraindicated: testing for IgM anti-WNV is important, since lgM is unable to cross the blood-brain barrier, it's detection in the CSF is a hallmark sign of WNV neuroinvasive disease; CSF is typically characterized by an increase of white blood cells (generally less than 500 cells $/ \mathrm{mm}^{3}$, but some patients have normal cell count, especially those with an immunocompromised status that are unable to mount a significant inflammatory response against WNV infection) - and increased protein levels, the latter being of greater magnitude in the case of WNV encephalitis; glucose levels are normal most of the time $8^{8,22,28,34}$.
Neuroimaging studies should be performed in order to help exclude differential diagnosis. In fact, imaging examinations (in particular magnetic resonance imaging - MRI) do not correlate exactly with active severe infection as they can remain without relevant findings during several weeks after onset of the disease $^{8}$. Concerning WNV encephalitis, the most characteristic MRI finding is bilateral signal abnormalities in the basal ganglia and the thalami ${ }^{35}$. In an AFP setting, signal abnormalities are usually found especially in the anterior spinal cord, representing damage in the anterior corticospinal tract ${ }^{21}$.

Electroencephalography in WNV encephalitis may present nonspecific abnormalities as generalized irregular slow waves, triphasic sharp waves, or it can even document seizures ${ }^{8,23}$.

When muscle weakness is observed and AFP is suspected, electrodiagnostic studies of the peripheral nervous system such as an electromyography or a nerve conduction study can be requested. Typically, motor axonopathy is shown, normally without any demyelinating abnormalities, with intact sensory function ${ }^{20,23}$.

\section{Treatment}

There is no specific treatment for WNV and usually only supportive measures are deployed to assist patients ${ }^{28}$. Pain and emesis management are the most commonly used, likewise ventilatory support in respiratory failure, prevention of superinfection and pressure sores or even seizures and intracranial pressure control ${ }^{30,33}$. Some agents as interferon alpha-2b, ribavirin, and intravenous immunoglobulin have been advanced as potential therapies but no studies showed a clear benefit in humans and most evidence for their proposed advantage comes from animal models or in vitro results ${ }^{15,36-38}$.

\section{Prognosis}

The general prognosis of a WNV infection is excellent taking into account the very low percentage of infected individuals that develop neuroinvasive disease, which is far more debilitating and life-threatening than other presentations ${ }^{15,28,38}$. Older age seems to be the most relevant prognostic factor ${ }^{39}$. Some medical conditions were showed to have an association with the development of WNV neuroinvasive disease ${ }^{40}$.

Follow-up of patients with neuroinvasive disease show that the majority of patients become functionally independent within several months to years, however a significant number might require long-term rehabilitation ${ }^{23,41}$. Mental status might remain persistently changed ${ }^{23}$. Neuroimaging studies might help predict prognosis ${ }^{35}$.

WNV meningitis is mostly associated with a positive outcome with a smaller chance of developing long-lasting neurological symptoms $^{23}$. WNV encephalitis' fatality rate is around $10 \%$ which can go up to $30 \%$ in older and/or immunocompromised patients ${ }^{36,40}$. Persistent physical complains are the most common findings ${ }^{24,41}$. Parkinsonism features and myoclonus are also reported ${ }^{23,38}$. Depression, apathy, and anxiety can be seen in the process of recovery from WNV encephalitis ${ }^{24,41}$. Cognitive deficits are also described, such as loss of memory and of thought $23,24,41$. The severity of the initial presentation is a debatable indicator of final outcome as patients with severe 
WNV encephalitis can recover without significant long-term functional losses ${ }^{21,38}$.

In the beginning of AFP's convalescence phase quality of the life could be compromised as the majority of patients still report muscle weakness which may require therapy to improve their physical impairment ${ }^{21,41}$. In the months postinfection, usually after 6 to 8 months, most patients recover from muscle weakness, varying with the extension of the disease ${ }^{21}$. Severe situations such as respiratory muscles involvement (responsible of $50 \%$ of deaths related with AFP) or quadriplegia are more difficult to overcome, in fact, previous health state before the WNV infection may never be reached ${ }^{21,38,41}$. But some patients recover successfully from dare clinical presentations ${ }^{21}$. The severity of the initial setting of APF is not the most reliable prognostic factor likewise WNV encephalitis, whereas electrodiagnostic studies might be more worthwhile, revelling the evolution of motor denervation when compared to initial tests ${ }^{21,42}$.

\section{Prevention}

Prevention is key to reduce the impact of WNV. Adopting individual precautions should follow the four D's rule: N,Ndiethyl-m-toluamide (DEET), an insect repellent; dress, clothes with long sleeves and long pants; drain standing water near one's residence; avoid being outdoors from dusk till dawn ${ }^{43,44}$. Community-based mosquitoes control policies take an important part in reducing the WNV's vector population by the means of insecticide spraying 33,44 .

Although being a demanding process, surveillance is always crucial to an effective and rapid response to an outbreak as it helps to predict an epidemic's magnitude improving the overall health system's preparedness ${ }^{4}$. A collaboration of several public institutions regarding human, animal and environmental health may improve the cost-effectiveness of WNV's infection control and prevention as the One Health approach ${ }^{45,46}$. Blood screening protocols significantly helped reducing the risk of transmission through transfusion ${ }^{46}$. Animal surveillance is also recommended: horses can be studied to determine the existence of WNV in a certain area - however, with the availability of an equine vaccine against WNV, the utility of this parameter is limited; searching for WNV infection in birds is useful in order to early warn public health services of WNV circulation, but due to logistical and economic costs this type of study is reserved to countries which experience large epidemics ${ }^{46}$.

\section{Future Perspectives}

WNV is subject to the constant changes the World has been facing the past decades, successfully adapting to the challenges presented by an ever-mutating society. Its geographic expansion is proof of the previous statement. What does the future hold for WNV, especially in the Iberian Peninsula? It is a difficult question to answer, however some predictions can be made regarding the current course of human development and its impact on the environment.

Higher density urban populations enable zoonotic diseases to flourish because transmission to humans becomes more frequent and mosquitoes have better breeding conditions specially in less sanitary conditions ${ }^{1,47}$. The population boom in certain parts of the globe will push for a greater land usage which if not planned and regulated will put in further contact humans and vectors ${ }^{48}$. Another consequence will be the increased movement of people for work purposes, tourism, or migration and the accompanying international traffic of goods which may play a part in expanding WNV and/or its vector to new areas ${ }^{1,47}$. Earth biosphere will be even more connected, and the smallest disturbance of balance might have a great impact on the general environment.

The increase in median temperatures and modifications of precipitation patterns across the globe will facilitate the spread of mosquitoes as they would be able to survive and thrive in areas that previously could not support their existence and will also alter birds' migration routes $1,48,49$. These factors would work together to globally extend the WNV period of activity and its geographic distribution.

Another future development regarding WNV infection prevention is related to the creation of a vaccine for human beings and some studies have been conducted ${ }^{50}$. However, the cost of designing a vaccine, the wide geographic area in which WNV is endemic, and the benign course in the large majority of the infected individuals are disadvantages towards such goal. ${ }^{50}$. It is also important to remember that WNV is capable of intrinsic change as well, by the means of genetic mutation. A new strain might develop sustained viremia in humans ending the status of "dead-end host" or the percentage of patients with neuroinvasive disease might increase if a more aggressive strain appears, for example'.

\section{CONCLUSION}

WNV was discovered 82 years ago and it has taught the scientific community that they should be prepared for the unexpected. In the presence of neurological symptoms and epidemiological links, WNV should be considered as a differential diagnosis, also in the Iberian Peninsula, as the vector Culex is widely distributed in the temperate regions. A serological analysis can make a difference between misdiagnosing and overtreating a patient. In conclusion, the dynamics of WNV have to be better understood in order to more effective measures can be implemented, whether in development of a vaccine, finding appropriate specific treatment or investing further on prevention. Each season of WNV is unique and provides a chance to gather more information, and one can only wonder how the future of WNV might play out.

\section{REFERENCES}

1. Braack L, Gouveia de Almeida AP, Cornel AJ, Swanepoel R, de Jager C. Mosquitoborne arboviruses of African origin: review of key viruses and vectors. Parasit Vectors. 2018; 11(1): 29.

2. Ze-Ze L, Proenca P, Osorio HC, Gomes S, Luz T, Parreira P, et al. Human case of West Nile neuroinvasive disease in Portugal, summer 2015. Euro Surveill. 2015; 20(38).

3. Lopez-Ruiz N, Montano-Remacha MDC, Duran-Pla E, Perez-Ruiz M, NavarroMari JM, Salamanca-Rivera C, et al. West Nile virus outbreak in humans and epidemiological surveillance, west Andalusia, Spain, 2016. Euro Surveill. 2018; 23(14).

4. Barzon L. Ongoing and emerging arbovirus threats in Europe. J Clin Virol. 2018; 107: 38-47

5. Reiter P. West Nile virus in Europe: understanding the present to gauge the future. Euro Surveill. 2010; 15(10): 19508. 
6. Rossi SL, Ross TM, Evans JD. West Nile virus. Clin Lab Med. 2010; 30(1): 47-65.

7. Sambri V, Capobianchi M, Charrel R, Fyodorova M, Gaibani P, Gould E, et al. West Nile virus in Europe: emergence, epidemiology, diagnosis, treatment, and prevention. Clin Microbiol Infect. 2013; 19(8): 699-704.

8. Sejvar JJ, Marfin AA. Manifestations of West Nile neuroinvasive disease. Rev Med Virol. 2006; 16(4): 209-24.

9. Schneider BS, Higgs S. The enhancement of arbovirus transmission and disease by mosquito saliva is associated with modulation of the host immune response. Trans R Soc Trop Med Hyg. 2008; 102(5): 400-8.

10. Pealer LN, Marfin AA, Petersen LR, Lanciotti RS, Page PL, Stramer SL, et al. Transmission of West Nile virus through blood transfusion in the United States in 2002. N Engl J Med. 2003; 349(13): 1236-45.

11. Iwamoto M, Jernigan DB, Guasch A, Trepka MJ, Blackmore CG, Hellinger WC, et al. Transmission of West Nile virus from an organ donor to four transplant recipients. N Engl J Med. 2003; 348(22): 2196-203.

12. CDC. West Nile virus infections in organ transplant recipients--New York and Pennsylvania, August-September, 2005. MMWR Morb Mortal Wkly Rep. 2005; 54(40): 1021-3.

13. Basavaraju SV, Kuehnert MJ, Zaki SR, Sejvar JJ. Encephalitis caused by pathogens transmitted through organ transplants, United States, 2002-2013. Emerg Infect Dis. 2014; 20(9): 1443-51

14. O'Leary DR, Kuhn S, Kniss KL, Hinckley AF, Rasmussen SA, Pape WJ, et al. Birth outcomes following West Nile Virus infection of pregnant women in the United States: 2003-2004. Pediatrics. 2006; 117(3): e537-45.

15. Davis LE, DeBiasi R, Goade DE, Haaland KY, Harrington JA, Harnar JB, et al. West Nile virus neuroinvasive disease. Ann Neurol. 2006; 60(3): 286-300.

16. Ferguson DD, Gershman K, LeBailly A, Petersen LR. Characteristics of the rash associated with West Nile virus fever. Clin Infect Dis. 2005; 41(8): 1204-7.

17. Zou S, Foster GA, Dodd RY, Petersen LR, Stramer SL. West Nile fever characteristics among viremic persons identified through blood donor screening. J Infect Dis. 2010; 202(9): 1354-61.

18. Petersen LR, Brault AC, Nasci RS. West Nile virus: review of the literature. Jama. 2013; 310(3): 308-15.

19. Sejvar JJ, Lindsey NP, Campbell GL. Primary causes of death in reported cases of fatal West Nile Fever, United States, 2002-2006. Vector Borne Zoonotic Dis. 2011; 11(2): 161-4.

20. Burton JM, Kern RZ, Halliday W, Mikulis D, Brunton J, Fearon M, et al. Neurological manifestations of West Nile virus infection. Can J Neurol Sci. 2004; 31(2): 185-93.

21. Sejvar JJ. Clinical manifestations and outcomes of West Nile virus infection. Viruses. 2014; 6(2): 606-23.

22. Kasper DL, Fauci AS, Hauser SL, Longo DL, Jameson JL, Loscalzo J. Harrison's Principles of Internal Medicine. 20 ed. New York: McGraw-Hill, Medical Pub. Division; 2018

23. Sejvar JJ, Haddad MB, Tierney BC, Campbell GL, Marfin AA, Van Gerpen JA, et al. Neurologic manifestations and outcome of West Nile virus infection. Jama. 2003; 290(4): 511-5.

24. Sejvar JJ, Curns AT, Welburg L, Jones JF, Lundgren LM, Capuron L, et al. Neurocognitive and functional outcomes in persons recovering from West Nile virus illness. J Neuropsychol. 2008; 2(Pt 2): 477-99.

25. Sejvar JJ, Leis AA, Stokic DS, Van Gerpen JA, Marfin AA, Webb R, et al. Acute flaccid paralysis and West Nile virus infection. Emerg Infect Dis. 2003; 9(7): 78893.

26. Sejvar JJ, Bode AV, Marfin AA, Campbell GL, Ewing D, Mazowiecki M, et al. West Nile virus-associated flaccid paralysis. Emerg Infect Dis. 2005; 11(7): 1021-7.

27. Jeha LE, Sila CA, Lederman RJ, Prayson RA, Isada CM, Gordon SM. West Nile virus infection: a new acute paralytic illness. Neurology. 2003; 61(1): 55-9.
28. Kramer LD, Li J, Shi PY. West Nile virus. Lancet Neurol. 2007; 6(2): 171-81.

29. Shukla B, Aguilera EA, Salazar L, Wootton SH, Kaewpoowat Q, Hasbun R. Aseptic meningitis in adults and children: Diagnostic and management challenges. J Clin Virol. 2017; 94: 110-4.

30. Alker A. West Nile virus-associated acute flaccid paralysis. BMJ Case Rep. 2015; 2015.

31. Hirota J, Shimizu S, Shibahara T. Application of West Nile virus diagnostic techniques. Expert Rev Anti Infect Ther. 2013; 11(8): 793-803.

32. Rizzoli A, Jimenez-Clavero MA, Barzon L, Cordioli P, Figuerola J, Koraka P, et al. The challenge of West Nile virus in Europe: knowledge gaps and research priorities. Euro Surveill. 2015; 20(20).

33. Solomon T, Ooi MH, Beasley DW, Mallewa M. West Nile encephalitis. Bmj. 2003 326(7394): 865-9.

34. Tyler KL, Pape J, Goody RJ, Corkill M, Kleinschmidt-DeMasters BK. CSF findings in 250 patients with serologically confirmed West Nile virus meningitis and encephalitis. Neurology. 2006; 66(3): 361-5.

35. Ali M, Safriel Y, Sohi J, Llave A, Weathers S. West Nile virus infection: MR imaging findings in the nervous system. AJNR Am J Neuroradiol. 2005; 26(2): 289-97.

36. Chowers MY, Lang R, Nassar F, Ben-David D, Giladi M, Rubinshtein E, et al. Clinical characteristics of the West Nile fever outbreak, Israel, 2000. Emerg Infect Dis. $2001 ; 7(4): 675-8$

37. Hrnicek MJ, Mailliard ME. Acute west nile virus in two patients receiving interferon and ribavirin for chronic hepatitis C. Am J Gastroenterol. 2004; 99(5): 957.

38. Hart J, Jr., Tillman G, Kraut MA, Chiang HS, Strain JF, Li Y, et al. West Nile virus neuroinvasive disease: neurological manifestations and prospective longitudinal outcomes. BMC Infect Dis. 2014; 14: 248

39. O'Leary DR, Marfin AA, Montgomery SP, Kipp AM, Lehman JA, Biggerstaff BJ, et al. The epidemic of West Nile virus in the United States, 2002. Vector Borne Zoonotic Dis. 2004; 4(1): 61-70.

40. Nash D, Mostashari F, Fine A, Miller J, O'Leary D, Murray K, et al. The outbreak of West Nile virus infection in the New York City area in 1999. N Engl J Med. 2001; 344(24): 1807-14

41. Patel H, Sander B, Nelder MP. Long-term sequelae of West Nile virus-related illness: a systematic review. Lancet Infect Dis. 2015; 15(8): 951-9.

42. Athar P, Hasbun R, Nolan MS, Salazar L, Woods SP, Sheikh K, et al. Longterm neuromuscular outcomes of west nile virus infection: A clinical and electromyographic evaluation of patients with a history of infection. Muscle Nerve. 2018; 57(1): 77-82.

43. Gujral IB, Zielinski-Gutierrez EC, LeBailly A, Nasci R. Behavioral risks for West Nile virus disease, northern Colorado, 2003. Emerg Infect Dis. 2007; 13(3): 419-25.

44. https://www.cdc.gov/features/stopmosquitoes/index.html; Centers for Disease Control and Prevention. [consulted in 23-12-2018]

45. Paternoster G, Babo Martins S, Mattivi A, Cagarelli R, Angelini P, Bellini R, et al. Economics of One Health: Costs and benefits of integrated West Nile virus surveillance in Emilia-Romagna. PLoS One. 2017; 12(11): e0188156.

46. Gossner CM, Marrama L, Carson M, Allerberger F, Calistri P, Dilaveris D, et al. West Nile virus surveillance in Europe: moving towards an integrated animal-humanvector approach. Euro Surveill. 2017; 22(18).

47. Gould E, Pettersson J, Higgs S, Charrel R, de Lamballerie X. Emerging arboviruses: Why today? One Health. 2017; 4: 1-13.

48. Kilpatrick AM. Globalization, land use, and the invasion of West Nile virus. Science. 2011; 334(6054): 323-7.

49. Semenza JC, Suk JE. Vector-borne diseases and climate change: a European perspective. FEMS Microbiol Lett. 2018; 365(2).

50. Collins MH, Metz SW. Progress and Works in Progress: Update on Flavivirus Vaccine Development. Clin Ther. 2017; 39(8): 1519-36 